\title{
Conceptual Model Designed to Evaluate the Interaction in Electronic Higher Education System of Iran
}

\author{
Mohammad Rahim Jafarizadeh \\ Department of Educational Sciences, Payame Noor University (PNU), Tehran, Iran, Corrwsponding Author
}

Bahman Saeedipor

Department of Educational Sciences, Payame Noor University (PNU), Tehran, Iran

Mohamad Reza Sarmadi

Department of Educational Sciences, Payame Noor University (PNU), Tehran, Iran

Zohreh Esmaeili

Department of Educational Sciences, Payame Noor University (PNU), Tehran, Iran

Doi:10.5901/mjss.2015.v6n6s6p394

\begin{abstract}
The aim of this study is to provide a conceptual model to assess the interaction of the electronic system of higher education in Iran. In this regard, two general questions raised and during the various stages of research it was attempted to be answered these questions: First question, the conceptual model for evaluating the interaction in Electronic higher education system of Iran what are the factors and components? Second; whether factors and components of the model are suitable for the measurement of target structures? Methods based on the objective of applied research and also based on the method data collection is descriptive. The study population consisted of all teachers and students of higher education electronic institutions of Iran that teaching and studying in the academic year 2014-2015 which among them, 620 people and the snowball sampling method has been selected as the sample. Collect information and respond to the first question from the study library and to respond to the second question from the questionnaire is used and the information collected were analyzed using the software Amos. After passing the various stages, model 3-factors - include; Status of network infrastructure, Status means and interactive tools as well as Status barriers using the interactive tools were extracted. According to this model each factor has two components, and each component can be evaluated using several criteria. The output of Amos analysis for each of the measurement structures, indicate that the conceptual model and all the models measurement, was appropriate to evaluate structure and can measure it entirely.
\end{abstract}

Keywords: E-learning, interaction, assessment, Designing, conceptual model, Higher education books

\section{Introduction}

Education is a process affecting the development of knowledge, skills, behaviors, attitudes and values. Nowadays art and science of teaching integrated with information and communication technology (ICT) and has created a new approach to learning called "e-learning" (Aury, 2005). The newest method in the evolution of distance education is e-learning (Liaw, 2008) which has been popular since the mid-1980s, and it has quickly been developed using Internet (Kanuka and Anderson, 2007). E-learning as a new paradigm in modern education, is a series of educational activities that with use of electronic devices is carried (Wange \& et al, 2011). Normark, \& Cetindamar (2005) defined E-learning as system's ability to e-transfer, manage, support and monitor learning and learning materials. 


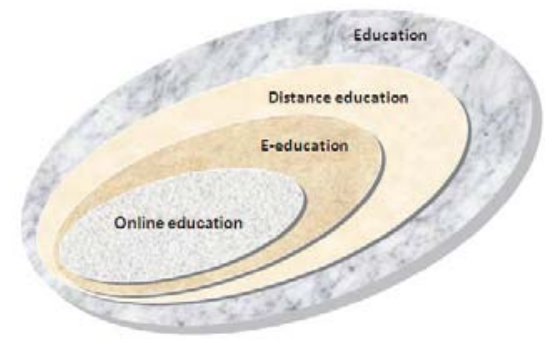

Figure 1. The status of e-learning in education

E-learning, is a hot topic in higher education and since the first web-based courses in the middle and late 1990s, so far as is developing a specific topic (Phil hill, 2012). Nowadays, e-learning has been introduced as an essential part of the learning experience of students in higher education (Oreh et al., 2015). E-learning support of individual learning, cooperative learning, learning content management, management activities and processes of learning, formal learning, informal learning at work and learning. (Valsamidis \& et al, 2014) and with regard to advantages such as; geographical access, control of learning (in terms such as flexibility, comfort), and cost-effectiveness in implementation and management; caused educational institutions and professional organizations to implement and expand the use of technologies that enables electronic learning of different platforms, in order to welcome it (Hu \& Hui, 2012).

Moreover, with globalization, exercised increasing pressure on institutions of higher education in different areas of the world to move towards the use of information and communication technology and access to their plans wider for audience (Torab khosi \& Marshal, 2009). In order to stay in the competition, universities should offer this type of training (Labay \& Comm, 2003). The use of this type of learning has been associated with some uncertainties and challenges, therefore, it is essential that parallel the virtual education to gaining a reputation, Factors such as relevance, quality and ease of use that learner driver to choose the kind of education as an alternative to traditional education is considered (Juwah, 2000).

Undoubtedly, one of the most important challenges is manner of interaction. Interaction is one of the most important factors of efficiency, effectiveness, quality, satisfaction, and ultimately is the success of any type of training and particular e-learning. Interaction as a key factor for success, satisfaction and Continuity and persistence learning in education is a complex concept (Bray, \& et al, 2008). Interaction as the main ingredient and master key the learning process of e-learning systems, is common point definitions of quality education and components evaluating the effectiveness and success in system of education.

In general, there are different views about the interaction in e-learning. Some has introduced as weaknesses of elearning and some use of ICT in e-learning, to consider an opportunity to provide more interaction and more effective (Alinezhad, 2012). Which of these views should be accepted it is necessary to judgment in this regard, the success of these system with using criteria and approaches based on the nature and concept of this type of education is examined.

The first step in evaluating any phenomenon is the existence of an appropriate model. Evaluation without a pattern is non-scientific and to expand phenomenon self-discretion and arbitrary action. On the other hand, moving towards quantitative measurement of various aspects of the programs, including those that have to move the path, otherwise it is necessary to wait for the judgment, which never can be an appropriate criterion for the assessment and programs.

This is important for several reasons in Iran. On one hand, e-learning is expanding rapidly in Iran so that most Iranian universities have opened the e-learning center within such a way that process of quantitative growth of 235 students in the electronic course in 2004 to 4918 cases in 2008 reached at several major public universities (Masoumi, D., 2010). And this trend is growing in the same way, so that by the end of August 2015 the number is 30480 persons (Institute for Research \& Planning in Higher Education, 2015). On the other hand, due to the lack of a framework and comprehensive tool for evaluating e-learning in Iran, scientific studies to determine and develop criteria for monitoring and evaluation, identifying the characteristics and standards defined and intelligent and realistic policy is necessary. And that the importance of addressing to the issue evaluation and develop a comprehensive and appropriate framework reveal further for evaluation e-learning and of programs in higher education institutions (Safavi \& Mohamadi, 2008).

The literature review of the issue has shown that this issue in the electronic system of higher education has two theoretical and practical importances. Since theory interaction in higher education need to clarify the concept and theory 
and model building. This is a serious issue that has been neglected. In the practical aspect, it has not been done any useful effort related to the research. Therefore, addressing this issue could lead to clarify and conduct research and studies of this kind, as well as a practical guide for authorities and operators to assess the key dimensions of quality and effectiveness of e-learning.

\section{Materials and Methods}

The general aim of this study is to "offer the conceptual model for assess of interaction in Electronic higher education system in Iran.

For this purpose, the following questions were raised: What are the conceptual model for evaluating cooperation in higher education e-Iranian components and elements? Are the main elements of the model correlated and what their ability to evaluate examined structures?

The research in terms of objective, is an applied one; and based on the method of data collection is descriptive (or non-experimental) and the correlation and in particular is based on structural equation modeling. Structural equation modeling is an approach of statistical population that assumptions about the relationships between variables observed and latent variables to be tested (Hooman, 2011). Through this approach, the acceptability of theoretical models tested in specific communities. The study statistical population consisted of all teachers and students in the academic year 20142015 in centers of Higher education have been taught virtual education. Sample size is 620 people that is used in their choice of snowball or chain sampling method.

\section{Findings}

First question: what are components and elements of the proposed model for the evaluation of interaction in Iranian higher e-education?

As it can be inferred from the definitions of e-learning ,this type of learning occurs in the context of the Internet, So quality and quantity of electronic and communication networks (Internet and telephone) as well as it can be an independent agent and as an underlying factor, complement and facilitator factor affecting the coverage and quality of educational interactions. The argument is that in e-learning courses the interaction between the students' and interaction between students with teachers, and other elements can be achieved when protected training with various tools. On the other hand, the mere availability of infrastructure, communications and electronics and the means of ensuring the quality is not the interaction. But in this regard there are obstacles that on exchange rate will affect and to be remembered as barriers to the use of vehicles and they can be named of them as an indicator of the rate of interaction in e-learning system.

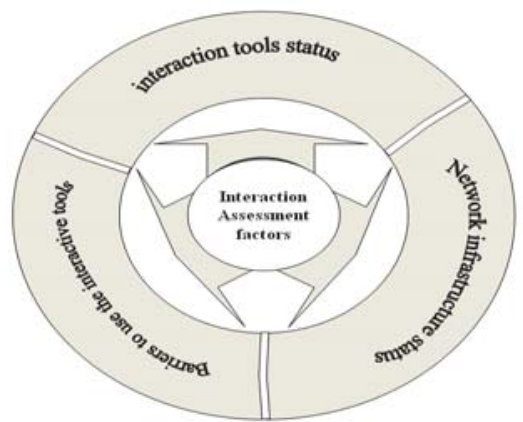

Figure 2. Factors of Evaluation the interaction in e-learning system

So it can be said that the interaction in e-learning system is a function of three major criteria:

\subsection{The status of network infrastructure}

The availability of electronic and internet infrastructure means that anyone with a minimum of effort and difficulty is capable of communicating with others and knowledge and he can propound his views in the other party or large populations. In this respect, internet can be a tool in order to upgrade the stability for strengthens of the general 
discussion on a wide range of issues (Saeidipuor, 2012).

Internet network compared with traditional media have specific and unique natural features such as interactivity, learning and decentralization, having discursive space which allows people to use for dialogue and discussion (Stanley\& et al, 2008). It is now a large amount of information accessed through the World Wide Web. The main reason for the growing use of the Internet is the ability to present and exhibit the color graphics, video, audio and text with hypertext links, (Hasanzadeh \& Navidi, 2010).

To measure the component, two indexes can be considered as follows:

\subsubsection{Accessibility (use}

The user that has the minimum hardware and software requirements he, she should be able to easily take advantage of all the different educational software and software without any problem and with need to minimal technical knowledge from the user is installed and runed. By studying literature and during the various stages, the following indicatorswere selected.

\subsubsection{Quality}

Quality of anything is a part of its nature and it is naturally considered a part of it. Cutler et al (1998) considered the quality as the technical and functional aspects. Technical quality of tangibility (what is provided the client or what gets to customer) is concerned. On the other hand, functional quality with dimensions of service such as events and interactions takes place between employees and customers during the confrontation with the service. In fact, it points how to provide customer service.

\subsection{Instruments and equipments to interact in e-learning system}

Information Technology; includes any equipment, system or subsystem of equipment that are automatically use for the acquisition, storage, manipulation, management, control, display, modify, exchange or receive data or information are handled by executive agencies (Ross, \& et al, 2005). Information technology is a combination of software and hardware for computer, telecommunications, the Internet and other communication technologies (Mercarder, \& et al, 2006). This collection features the creation of conditions such as the ability to communicate with several people at the same time, connection flexible in terms of time and space, and being able to communicate face to face, provide a rich communication environment (Wang \& Soong, 2008). Interaction tools in e-learning can be divided into two major categories: Asynchronous interaction tools and synchronous interaction tools.

\subsubsection{Asynchronous interaction tools}

Tools that can provide the kind of interaction that it is not clear at the time and place and people whenever and wherever they want, can enter the network and exchange information. Express mail services, discussion page, Wikipedia, news groups, podcasts and Youtab including asynchronous communication tools in this environment are considered.

\subsubsection{Synchronous interaction tools}

Tools that can provide the kind of interaction in which people (including teachers, students, professionals, consultants, etc.) to be alive and at the same time and able to communicate and face-to-face (but from network PCs) with each other to exchange ideas and opinions or information. Chat room, audio-visual conferencing, whiteboard tools and online meeting tools, are examples of communication tools at the same time.

\subsection{Barriers to the use of e-learning tools}

According to Bhattacherjee \& premkumar use of information technology in the research of information systems is a key dependent variable. And tend to use a reliable predictor of actual use of information technology (Sun, 2003). Despite the availability and supply of tools and means of communication and interaction in e-learning system; various factors may cause lake of the adoption and use of technology that can be discussed in both individual and non-individual issues them. 


\subsubsection{Individual barriers}

Among the numerous individual issues and problems that were identified in theory, technology literacy (knowledge, technology), knowledge of English (general, specialized and technical), and fear of technology was more prominent. The ability to think about Information and the power of retrieval and use it as one of the necessities of life in relation to others in an interactive two-way or multi-way can be considered information and communication technology literacy (Seraj, 2004). About knowledge of English is clear that now is used in English as the language of technology and scientific concepts. Computer anxiety is mental state of people who have negative reactions to the use of computers. Moreover, it has been described as fear of interacting with a computer and real threat which is created by computer.

\subsubsection{Non-personal barriers}

In addition to the above, the following can be considered: The adequacy of tools and devices so that other various groups involved in e-learning can be used without restrictions. Easiness (installed and running), charm, security, multimedia, and financial and investment poverty are those things that influence the amount of use of e-learning tools.

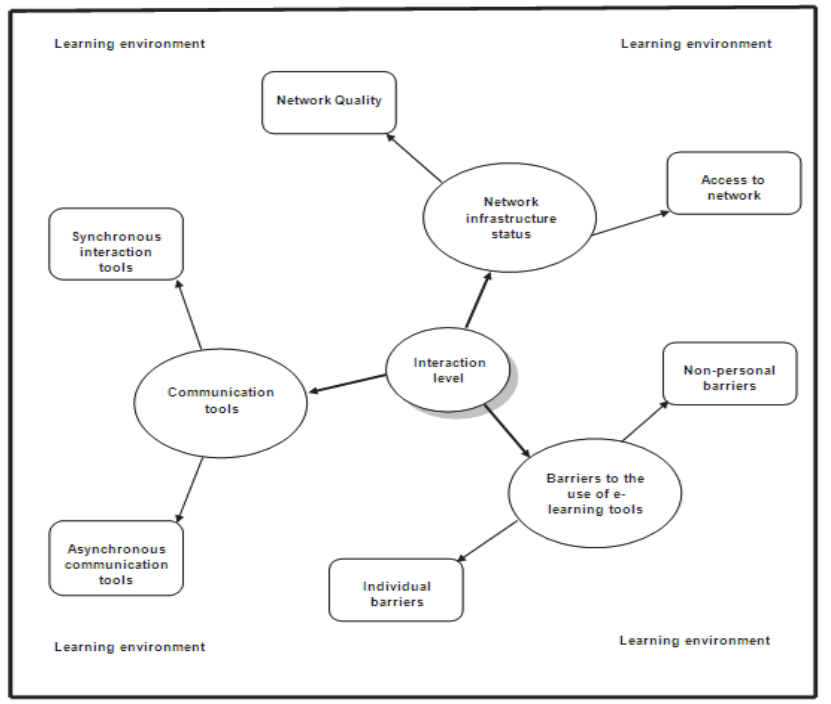

Figure 3. The conceptual model of Assessment of interaction in Iranian Higher e-education system.

Second question: Are the main elements of the model correlated and what their ability to evaluate examined structures? In order to respond to the question of whether any of the developed measurement models of structures investigated have the minimum scientific standards or not, it is necessary to measure each of the models separately (Ghasemi, 2013). Accordingly, on part of whole, first measurement models sub construction and larger structures examined and in the end, we examined the final version of the study model.
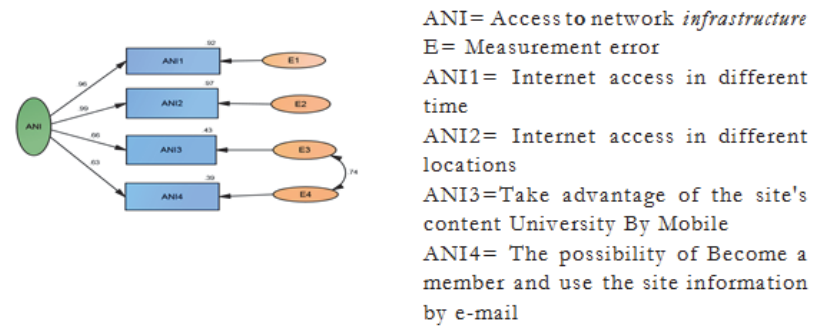

Figure 4. Model of Measure Access to network infrastructure access 
Table1. Fit Indices of factor of Access to network infrastructure

\begin{tabular}{|l|l|l|l|l|l|l|l|l|l|l|}
\hline Type & \multicolumn{4}{|c|}{ Absolute Fit Indices } & \multicolumn{4}{l|}{ Comparative Fit Indices } & \multicolumn{2}{l|}{ Parsimonious Fit Indices } \\
\hline Statistics & Chi & Df & Chi/ Df & RMSEA & GFI & NFI & CFI & RMR & PCFS & PNFI \\
\hline Quantityl & 1.26 & 1 & 1.261 & 0.021 & 0.999 & 1.000 & 1.000 & 0.001 & 0.167 & 0.167 \\
\hline
\end{tabular}

IAmos output results for the evaluation model access component (Figure4 and table1); shows the because that absolute fitted indices such as the value of $\times 2 / D f$, along with other indicators, such as the root mean square error (RMSEA); with regard to the $90 \%$ confidence interval and the comparative fit index (GFI, NFI, CFI) with cut-off point of $90 \%$ is in a very favorable status. Although thrifty fitting indicators (PCFS, PNFI) suggests being thrifty researcher unleashing parameters. However, the conclusions of measures indexes of model indicate that it largely can be acceptable and valid for assessing the access component.
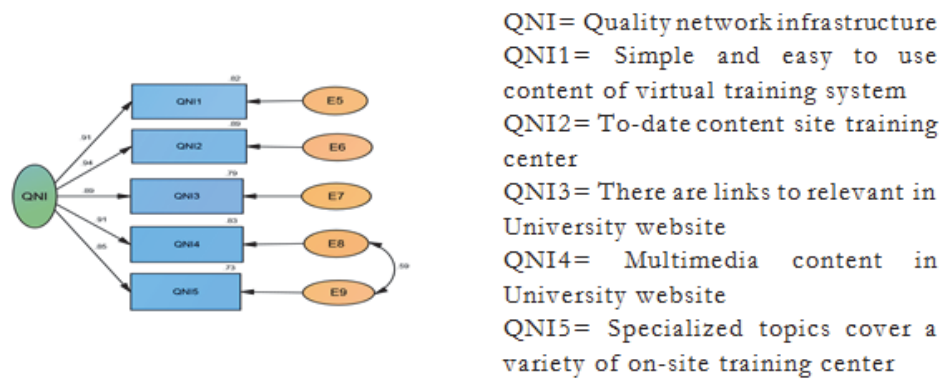

Figure 5. The assessment model of Quality of network infrastructur

Table 2. Fit Indices of Quality network infrastructure factor

\begin{tabular}{|c|c|c|c|c|c|c|c|c|c|c|}
\hline Type & \multicolumn{4}{|c|}{ Absolute Fit Indices } & \multicolumn{4}{c|}{ Comparative Fit Indices } & \multicolumn{2}{c|}{ Parsimonious Fit Indices } \\
\hline Statistics & Chi & Df & Chi/ Df & RMSEA & GFI & NFI & CFI & RMR & PCFS & PNFI \\
\hline Quantity & 19.934 & 4 & 4.984 & 0.08 & 0.987 & 0.995 & 0.996 & 0.004 & 0.398 & 0.398 \\
\hline
\end{tabular}

Amos output results of the model evaluation component Quality network infrastructure (figure5 and table2); shows the because that absolute fitted indices such as the value of $x 2 / D f$, along with other indicators, such as the root mean square error; with regard to the $90 \%$ confidence interval and the comparative fit index with cut-off point of $90 \%$ is in a very favorable status. Although thrifty fitting indicators; suggests being thrifty researcher unleashing parameters. conclusions of measures indexes of model indicate that it largely can be acceptable and valid for assessing the Quality network infrastructure component.

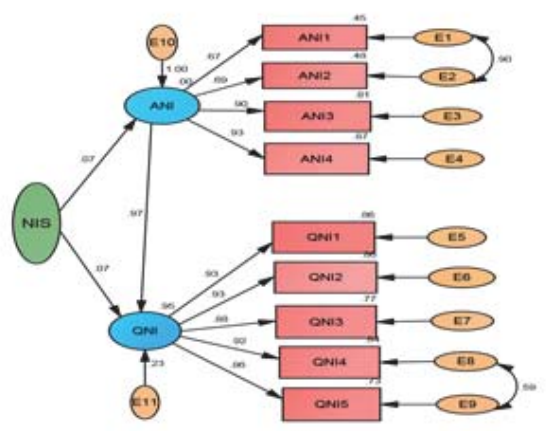

Figure 6. The assessment model of Network Infrastructure Status 
Table 3. Fit Indices of factor of Network Infrastructure Status

\begin{tabular}{|c|c|c|c|c|c|c|c|c|c|c|}
\hline Type & \multicolumn{4}{|c|}{ Absolute Fit Indices } & \multicolumn{3}{c|}{ Comparative Fit Indices } & \multicolumn{3}{c|}{ Parsimonious Fit Indices } \\
\hline Statistics & Chi & Df & Chi/Df & RMSEA & GFI & NFI & CFI & RMR & PCFS & PNFI \\
\hline Quantity & 111.92 & 27 & 4.145 & 0.09 & 0.933 & 0.974 & 0.978 & 0.015 & 0.733 & 0.731 \\
\hline
\end{tabular}

results of the model evaluation component Network Infrastructure Status (figure6 and table3); Suggests that that model fit indices such as the amount of $x 2 / D f$ along with other indicators, such as the root mean square error ; with regard to the $90 \%$ confidence interval, comparative fit index with cut-off point of $90 \%$ and parsimonious fit indices (PCFS, PNFI) with cut-off point 0.5 all is in very good condition and is confirmed this result that is considered model acceptable and to measure the components of Network Infrastructure Status is valid and can well weigh it.

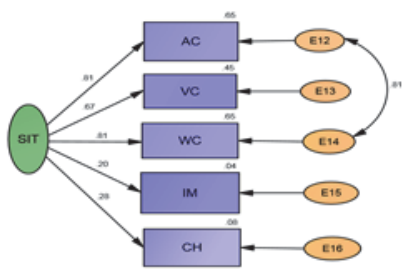

$$
\begin{aligned}
& \text { SIT }=\quad \text { synchronous } \\
& \text { interaction tools } \\
& \mathrm{AC}=\text { Audio Conferencing } \\
& \mathrm{VC}=\text { Video Conferencing } \\
& \mathrm{WC}=\text { Web conference } \\
& \mathrm{IM}=\text { Web conference } \\
& \mathrm{CH}=\text { chat }
\end{aligned}
$$

Figure 7. The assessment model of synchronous interaction tools

Table 4. Fit Indices of factor of the synchronous interaction tools

\begin{tabular}{|c|c|c|c|c|c|c|c|c|c|c|}
\hline Type & \multicolumn{3}{|c|}{ Absolute Fit Indices } & \multicolumn{4}{c|}{ Comparative Fit Indices } & \multicolumn{2}{c|}{ Parsimonious Fit Indices } \\
\hline Statistics & Chi & Df & Chi/Df & RMSEA & GFI & NFI & CFI & RMR & PCFS & PNFI \\
\hline Quantity & 22.861 & 5 & 4.572 & 0.07 & 0.984 & 0.985 & 0.988 & 0.04 & 0.494 & 0.493 \\
\hline
\end{tabular}

Amos output results of the model evaluation component synchronous interaction tools (figure7 and table4) shows that model fit indices such as the amount of $x 2 / D f$ along with other indicators, such as the root mean square error; with regard to the $90 \%$ confidence interval, comparative fit index with cut-off point of $90 \%$ and parsimonious fit indices with cut-off point 0.5 all is in very good condition and is confirmed this result that is considered model acceptable and to measure the components of synchronous interaction tools and valid for assessing this component.

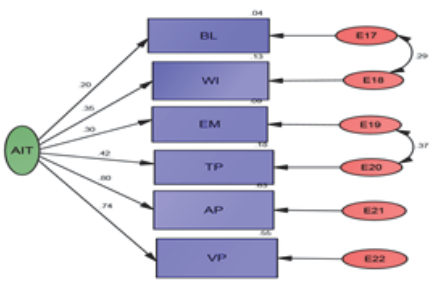

$$
\begin{aligned}
& \mathrm{AIT}=\text { Asynchronous interaction } \\
& \text { tools } \\
& \mathrm{BL}=\mathrm{Blog} \\
& \mathrm{WI}=\mathrm{Wiki} \\
& \mathrm{EM}=\text { Email } \\
& \mathrm{TP}=\text { Word processor } \\
& \mathrm{AP}=\text { Sound Processor } \\
& \mathrm{VP}=\text { Sound Processor }
\end{aligned}
$$

Figure 8. The assessment model of Asynchronous interaction tools

Table 5. Fit Indices of factor of Asynchronous interaction tools

\begin{tabular}{|c|c|c|c|c|c|c|c|c|c|c|}
\hline Type & \multicolumn{3}{|c|}{ Absolute Fit Indices } & \multicolumn{4}{c|}{ Comparative Fit Indices } & \multicolumn{2}{c|}{ Parsimonious Fit Indices } \\
\hline Statistics & Chi & Df & Chi/Df & RMSEA & GFI & NFI & CFI & RMR & PCFS & PNFI \\
\hline Quantity & 41.045 & 9 & 4.561 & 0.07 & 0.979 & 0.941 & 0.953 & 0.07 & 0.572 & 0.564 \\
\hline
\end{tabular}

Results of the model evaluation component asynchronous interaction tools (figure8 and table5) Suggests that model fit indices such as the amount of $x 2 / D f$ along with other indicators, such as the root mean square error; with regard to the 
$90 \%$ confidence interval, comparative fit index with cut-off point of $90 \%$ and parsimonious fit indices with cut-off point 0.5 all is in very good condition and is confirmed this result that is considered model acceptable and to measure the components of asynchronous interaction tools is valid and can well weigh it.

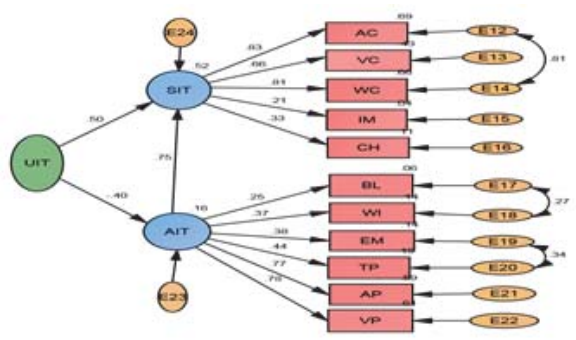

Figure 9. The assessment model of status of use of interaction tools

Table 6. Fit Indices of factor of status of use of interaction tools

\begin{tabular}{|c|c|c|c|c|c|c|c|c|c|c|}
\hline Type & \multicolumn{4}{|c|}{ Absolute Fit Indices } & \multicolumn{3}{c|}{ Comparative Fit Indices } & \multicolumn{3}{c|}{ Parsimonious Fit Indices } \\
\hline Statistics & Chi & Df & Chi/ Df & RMSEA & GFI & NFI & CFI & RMR & PCFS & PNFI \\
\hline Quantity & 686.84 & 42 & 6.83 & 0.09 & 0.925 & 0.888 & 0.902 & 0.021 & 0.689 & 0.678 \\
\hline
\end{tabular}

Amos output results of the model evaluation component status of use of interaction tools (figure9 and table6) Suggests that model fit indices such as the amount of $x 2 / D f$ along with other indicators, such as the root mean square error; with regard to the $90 \%$ confidence interval, comparative fit index with cut-off point of $90 \%$ and parsimonious fit indices with cut-off point 0.5 all is in very good condition and is confirmed this result that is considered model acceptable and to measure the components of status of use of interaction tools is valid and can well weigh it.
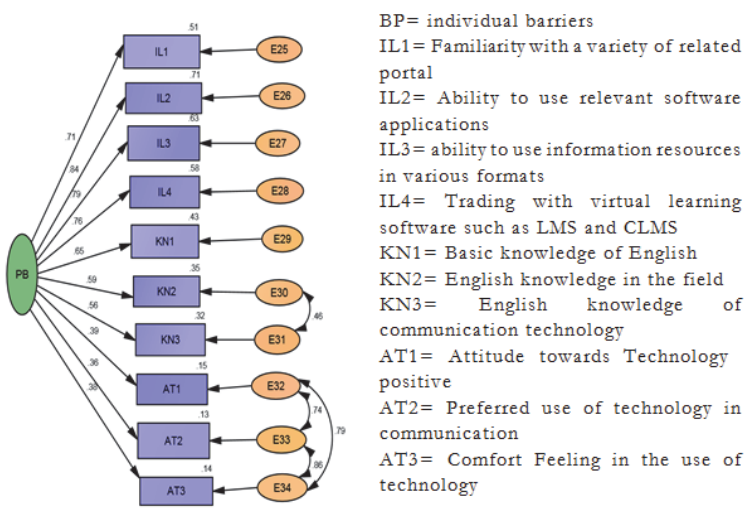

Figure 10. The assessment model of individual barriers

Table 7. Fit Indices of factor of individual barriers

\begin{tabular}{|c|c|c|c|c|c|c|c|c|c|c|}
\hline Type & \multicolumn{4}{|c|}{ Absolute Fit Indices } & \multicolumn{4}{c|}{ Comparative Fit Indices } & \multicolumn{3}{c|}{ Parsimonious Fit Indices } \\
\hline Statistics & Chi & Df & Chi/Df & RMSEA & GFI & NFI & CFI & RMR & PCFS & PNFI \\
\hline Quantity & 94.24 & 32 & 2.945 & 0.03 & 0.889 & 0.900 & 0.907 & 0.032 & 0.645 & 0.640 \\
\hline
\end{tabular}

Results of the model evaluation component individual barriers (figure10 and table7) shows that model fit indices such as 
the amount of $x 2 / D f$ along with other indicators, such as the root mean square error; with regard to the $90 \%$ confidence interval, comparative fit index with cut-off point of $90 \%$ and parsimonious fit indices with cut-off point 0.5 all is in very good condition and is confirmed this result that is considered model acceptable and to measure the components of individual barriers are valid and can well weigh it.

Amos output results of the model evaluation component non-personal barriers (figure11 and table8) Suggests that absolute fitted indices such as the value of $x 2 / D f$, along with other indicators, such as the root mean square error; with regard to the $90 \%$ confidence interval and the comparative fit index with cut-off point of $90 \%$ is in a very favorable status. Although thrifty fitting indicators suggests being thrifty researcher unleashing parameters. However, the conclusions of measures indexes of model indicate that it largely can be acceptable and valid for assessing the non-personal barriers component.
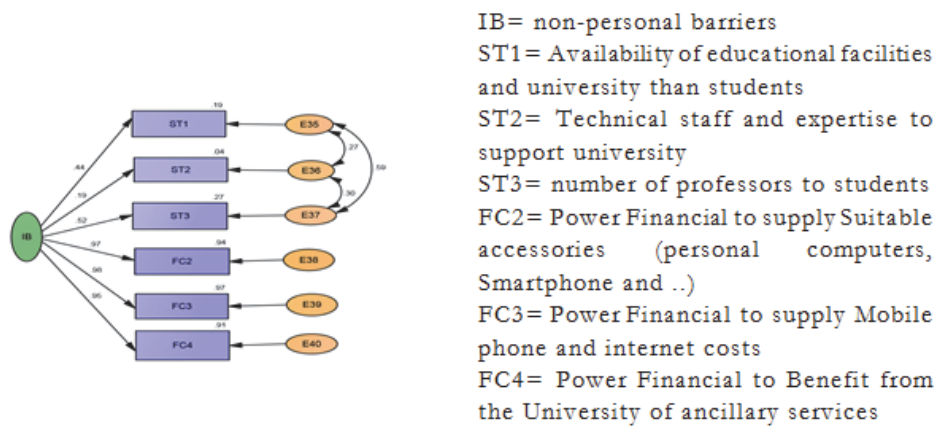

Figure 11. The assessment model of non-personal barriers

Table 8. Fit Indices of factor of non-personal barriers

\begin{tabular}{|c|c|c|c|c|c|c|c|c|c|c|}
\hline \multicolumn{11}{|c|}{ Table 8. Fit Indices of factor of non-personal barriers } \\
\hline Type & \multicolumn{4}{|c|}{ Absolute Fit Indices } & \multicolumn{4}{|c|}{ Comparative Fit Indices } & \multicolumn{2}{|c|}{ Parsimonious Fit Indices } \\
\hline Statistics & Chi & $D f$ & Chi/Df & RMSEA & GFI & $N F I$ & $\mathrm{CFI}$ & RMR & PCFS & PNFI \\
\hline Quantity & 15.586 & 6 & 2.598 & 0.051 & 0.992 & 0.996 & 0.997 & 0.007 & 0.398 & 0.399 \\
\hline
\end{tabular}

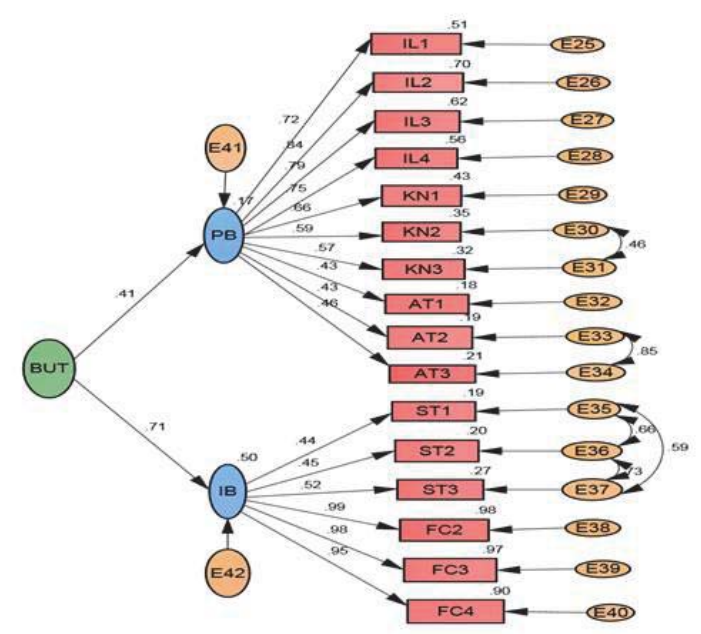

Figure 12. The assessment model of barriers of use of interaction tools 
Table 9. Fit Indices of factor barriers of use of interaction tools

\begin{tabular}{|c|c|c|c|c|c|c|c|c|c|c|}
\hline Type & \multicolumn{4}{|c|}{ Absolute Fit Indices } & \multicolumn{4}{c|}{ Comparative Fit Indices } & \multicolumn{3}{c|}{ Parsimonious Fit Indices } \\
\hline Statistics & Chi & Df & Chi/ Df & RMSEA & GFI & NFI & CFI & RMR & PCFS & PNFI \\
\hline Quantity & 513.8 & 98 & 5.345 & 0.05 & 0.795 & 0.935 & 0.943 & 0.018 & 0.765 & 0.744 \\
\hline
\end{tabular}

BUT= status of barriers of use of interaction tools

Results of the model evaluation component barriers of use of interaction tools (figure12 and table9) shows that model fit indices such as the amount of $x 2 /$ Df along with other indicators, such as the root mean square error (RMSEA); with regard to the $90 \%$ confidence interval, comparative fit index (GFI, NFI, CFI) with cut-off point of $90 \%$ and parsimonious fit indices (PCFS, PNFI) with cut-off point 0.5 all is in very good condition and is confirmed this result that is considered model acceptable and to measure the components barriers of use of interaction tools valid and can well weigh it.

Amos output results of the model evaluation interaction (figure13 and table10) shows that model fit indices such as the amount of $x 2 / D f$ along with other indicators, such as the root mean square error (RMSEA); with regard to the $90 \%$ confidence interval, comparative fit index (GFI, NFI, CFI) with cut-off point of $90 \%$ and parsimonious fit indices (PCFS, $P N F I$ ) with cut-off point 0.5 all is in very good condition and is confirmed this result that is considered model acceptable and to measure the interaction and valid for assessing the it.

Table 10. Fit Indices of assessment model of interaction in Iranian higher e- education

\begin{tabular}{|l|l|l|l|l|l|l|l|l|l|l|}
\hline Type & \multicolumn{4}{|l|}{ Absolute Fit Indices } & \multicolumn{4}{l|}{ Comparative Fit Indices } & \multicolumn{2}{l|}{ Parsimonious Fit Indices } \\
\hline Statistics & Chi & Df & Chi/ Df & RMSEA & GFI & NFI & CFI & RMR & PCFS & PNFI \\
\hline Quantity & 3599 & 569 & 6.325 & 0.09 & 0.879 & 0.924 & 0.947 & 0.018 & 0.765 & 0.744 \\
\hline
\end{tabular}

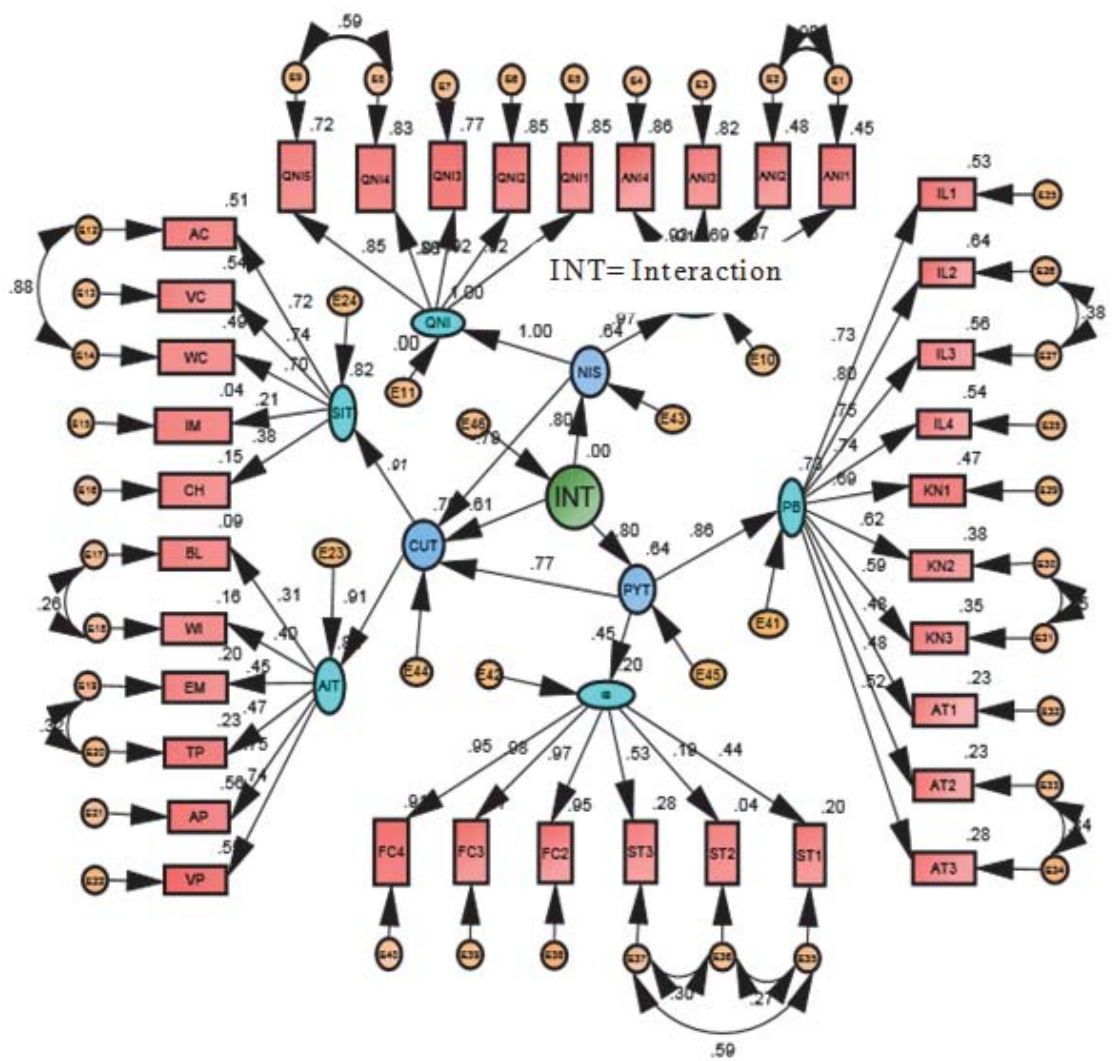

Figure 13. The assessment model of the interaction in Iranian higher e- education 


\section{Discussion and Conclusion}

Interaction (both quality and quantity) is the most important challenges in electronic higher education system. Although, there are some debates related to interaction issues theoretically, and some have referred to it as a strong point and some other as a disadvantage of e-learning. These conclusions are based on rather than evidence objective, tangible and practical activities in the field of assessment based on the views of people based on dominant approach in the field; so self-jurisprudential, personal judgment and taste function; they comment. This trend with regard to the rapid expansion of e-learning in higher education and the need to respond to the challenges posed on about the situation interaction was not appropriate and must supply about the requirements, standards, and design pattern assessment of to be practical interaction.

This issue in higher e-education in Iran for reasons such as rapid growth this type of education and a leap forward in the number of students, the poverty detailed theoretical and conceptual frameworks and study the poverty of comprehensive tools for assessment is more important. Therefore, in this research it was tried to examine scientific knowledge scientific knowledge features and standards and facts to modeling in the field of assessment interaction in electronic higher education. Accordingly, with studying the theoretical fundamentals, a comprehensive conceptual pattern of factors; components and elements effecting in assessing interaction in the higher education Iran electronic system of extracting and using structural equation model was tested through the application Amos. Pattern design concept has three factors, multiple dimensions and indicators, so it concluded all aspects of interaction for evaluation. Amos results about the testing indicate that all models measure the model constructs having the necessary solidarity, is appropriate to assess interaction. This means that it can properly measure the interaction.

With respect to that research about the modeling the interaction assessment in electronic higher education system has been limited and it has been a case study and no one has attended to this issue comprehensively, So the results these studies are not comparable with previous research and that is the limitations of this study.

\section{References}

Siraj, Shahnaz. (1383), The concept of information literacy and information literate -a-glance of library view. E-magazine Nama, (3), 6-11 Saeidipour, Bahman, Maryam Eslam panah, Azad Darabi (2012). The relationship between rate of the use of Internet social participation of students University of Payam Noor in Kermanshah. Journal of Learning and Teaching. The first year, first number.

Safavi, Aliakbar, Mehdi Mohamadi (2008), Accreditation and monitoring of e-learning courses in Iran, Second conference e-learning, Zahedan, pp:215-227.

Ghasemi, Vahid (2014). Structural modeling in social research application Amos Graphics, Tehran, Sociologists Publications, Second Edition.

Alinezhad, Mehrangiz; Sarmadi, Mohamadreza; Zandi; Bahman \& Shabiri, seyed mohamad (2012). Information literacy level and its role in e-learning training process of students, Journal of information and public libraries.

Institute for Research \& Planning in Higher Education, 2015.

Hooman, Heydarali (2012). Structural equation modeling using LISREL software, Tehran: Samt Publishing.

Aury MC. (2005). Agricultural Education Students' Perception of WebCT in Puerto Rico. Paper presented at the IMPACT, 7th Annual WebCT User Conference; 2005; San Francisco, California. Available from:

http://webct.confex.com/webct/2005/preliminaryprogram/abstract_1176.htm

Bray, E., Aoki, K., \& Dlugosh, L. (2008). Predictors of learning satisfaction in Japanese online distance learners. International Review of Research in Open \& Distance Learning, 9(3), 1-24.

Juwah,c. (2000). Developing effective online tutoring. in c. Higgison (ED.) ,practitioners experiences in online tutoring : case studies from the OTiS e-Workshop

Kanuka, H. and Anderson, T. (2007); "Ethical Issues in Qualitative Elearning Research"; International Journal of Qualitative Methods, Vol. 6, No. 2.

Hasanzadeh M, Navidi F. A Comparative Study on the Application of Different Methods for Evaluating the Accessibility of Websites (Case Study: Websites of Ministries of Iranian Government). Research on information science and public libraries 2010; 16(2): 527. [Persian]

Liaw, S. S. (2008); "Investigating Students' Perceived Satisfaction, Behavioral Intention, and Effectiveness of E-learning: A Case Study of the Blackboard System"; Computers \& Education, Vol. 51, pp. 864-873.

Masoumi, D. (2010). E-learning in Iran-I a breakthrough to ICT-based initiatives in an educational system, University of Gothenburg.pp:229- 250. In: Demiray, Ugur (2010). Cases on challenges facing e-learning and national development: institutional studies and practices. Volume: I. Anadolu University. Eskisehir-Turkey.

Normark, O. R., \& Cetindamar, D. (2005). E-learning in a competitive firm setting. Innovations in Education \& Teaching International, $42(4), 325-335$.

Phil hill (2012). "online education delivery models: A descriptive view", EDUCAUSE Review (November/December 2012), 
http://www.educause/edu/ero/online-educational-delivery-model-descriptive-view.

Ross, Katzke, Johnson, Swanson, Stone burner, Rogers, lee (2005) «information Security» NIST Special Publication PP. 800 - 853.

Stanley, J.Woody \& wear, Christopher (2008). The Effect of Internet Use On Political Participation Retieved January 27,2008 from.

Sun H.( 2003). An integrative analysis of TAM: Toward a deeper understanding of technology acceptance model. Proceeding of the Americas Conference on Information Systems (AMCIS) '03: Tampa, FL.

Turab-Nkhosi, D. \& Marshall, S. (2009). Quality management in course development and delivery at the University of the West Indies Distance Education Centre. Quality Assurance in Education. 17(3):264-280.

Valsamidis, S., Kazanidis, I., Petasakis, I., Kontogiannis, S., \& Kolokitha, E. (2014). E-Learning Activity Analysis. Procedia Economics and Finance, 9, 511-518.

Wang, H. Jia, M. W. Ran, J.H. Yang, J. Liao, and D. Chiu, (2011). Design of a performance-oriented workplace e-learning system using ontology. Expert Systems with Applications. 38, 3372-3382.

Wang, S \& Song, H (2008). Learning community and networked learning community. In Lawrence A. Tomei. Encyclopedia of information technology curriculum integration. Hershey: Information Science reference.

Zamfiroiu, A., \& Sbora, C. (2014). Statistical analysis of the behavior for mobile E-learning. Procedia Economics and Finance, 10, 237243.

UHu, P. J. H., \& Hui, W. (2012). Examining the role of learning engagement in technology-mediated learning and its effects on learning effectiveness and satisfaction. Decis. Support Syst., 53, 782-792. 